\title{
Phytoestrogens in milk: Overestimations caused by contamination of the hydrolytic enzyme used during sample extraction
}

\author{
L. Bláhová, ${ }^{*}$ J. Kohoutek, ${ }^{*}$ T. Procházková, ${ }^{*}$ M. Prudíková, $†$ and L. Bláha*1 \\ ${ }^{*}$ Faculty of Science, Research Centre for Toxic Compounds in the Environment, Masaryk University, Kamenice 753/5, Building A29, \\ CZ62500 Brno, Czech Republic \\ †Faculty of Agronomy, Department of Morphology, Physiology and Animal Genetics, Mendel University, Zemědělská 1, CZ613 00 Brno, \\ Czech Republic
}

\begin{abstract}
Isoflavones are natural phytoestrogens with antioxidant and endocrine-disrupting potencies. Monitoring of their levels is important to ensure the high quality and safety of food, milk, and dairy products. The efficiency and accuracy of phytoestrogen analyses in complex matrices such as milk depend on the extraction procedure, which often uses hydrolysis by means of the $\beta$-glucuronidase/sulfatase enzyme originating from Helix pomatia. The present study reveals that the commercially available hydrolytic enzyme is contaminated by several phytoestrogen isoflavones (genistein, daidzein, formononetin, and biochanin A) and their metabolite equol, as well as flavones (naringenin and apigenin) and coumestrol. We show that the concentrations of daidzein and genistein in the enzyme could have impaired the results of analyses of the main isoflavones in several previously published studies. Of 8 analyzed compounds, only equol was confirmed in the present study and it serves as a reliable marker of phytoestrogens originating from cow feed. Critical reassessment of phytoestrogen concentrations in milk is needed because several previously published studies might have overestimated the concentrations depending on the extraction procedure used.
\end{abstract}

Key words: bovine milk, phytoestrogen, mass spectrometry, equol

\section{INTRODUCTION}

Endocrine disruptors (ED), including compounds of natural origin, may affect the hormonal system and pose risks to human health via the food chain. For example, isoflavones (i.e., phytoestrogens from a group of phenolic compounds) have the capacity to affect the

Received January 21, 2016.

Accepted May 21, 2016.

${ }^{1}$ Corresponding author: blaha@recetox.muni.cz endocrine system as well as the antioxidant status. They are naturally widespread in the human diet, including vegetables, milk, and milk products (Antignac et al., 2003). Specifically, dairy cow milk has recently been shown to contain various phytoestrogens, including coumestans, lignans, and, most importantly, isoflavones (genistein, daidzein, formononetin, and biochanin A) and also a metabolite of formononetin, isoflavan equol. The phytoestrogens were found to be transferred to milk after digestion of ruminant feedstuff and to reach concentrations of up to hundreds of micrograms per liter of milk (Steinshamn et al., 2008; Andersen et al., 2009; Höjer et al., 2012; Njåstad et al., 2014). Isoflavones occur in biological fluids in 2 major forms. From the rumen, they are absorbed mainly as aglycones (i.e., the basic nonconjugated form). Then, metabolization in animals leads to the formation of conjugates with sulfate or glucuronic acid, and these metabolites are transferred to milk (Njåstad et al., 2014). Aglycones represent the biologically active form associated with the ED properties of isoflavones (Antignac et al., 2009).

Recently, several methods using liquid chromatography coupled with tandem mass spectrometry (LC-MS / MS) have been described for the analysis of phytoestrogens in milk (Antignac et al., 2003; Krajčová et al., 2010; Zafra-Gómez et al., 2010; Daems et al., 2015). The efficiency and accuracy of analyses also depend on the extraction of aglycones or conjugates, which requires the hydrolysis of phytoestrogens from their conjugated forms. The efficient hydrolysis and release of aglycones is achieved by means of strong acids or enzymatic reaction (Santos-Buelga et al., 2012). The most recent studies of isoflavones in milk employed specific enzymes, particularly $\beta$-glucuronidase/sulfatase originating from the common snail, Helix pomatia (Steinshamn et al., 2008; Andersen et al., 2009; Krajčová et al., 2010; Njåstad et al., 2014). The enzyme was first used for the deconjugation of similar compound classes such as steroids (Antignac et al., 2009; Deceuninck et al., 2013), and it was applied to analyses of phytoestrogens in plasma and urine. However, limitations of using hy- 
drolases have also been reported. For example, Taylor et al. (2005) in their optimization study with urine and plasma showed contamination of hydrolytic enzyme $\beta$-glucuronidase from $H$. pomatia $(100,400 \mathrm{U} / \mathrm{mL}$; type HP-2) by genistein, daidzein, and equol. In another study describing the purification of $\beta$-glucuronidase $(H$. pomatia; type HP-2), genistein was the major isoflavone contaminant of the enzyme (Grace and Teale, 2006).

Interestingly, several studies that investigated phytoestrogens in food and milk did not provide detailed information on the source and purity of the hydrolytic enzyme, which could critically affect the results of phytoestrogen analysis in milk, as is shown in the present study. Our study describes in detail contamination of the commonly used $\beta$-glucuronidase/sulfatase enzyme by several phytoestrogens such as coumestrol, naringenin, and apigenin, as well as the isoflavones genistein, daidzein, formononetin, and biochanin A. The concentrations of some interfering compounds in the enzyme were within the same levels as reported in milk extracted by the $H$. pomatia hydrolytic enzyme, which could have broad consequences for the assessment of food quality and safety.

\section{MATERIALS AND METHODS}

\section{Reagents and Chemicals}

The reagents (acetic acid, sodium hydroxide, dimethyl sulfoxide) and solvents (methanol, acetone, ethylacetate, formic acid) were of analytical or LC/MS grade and were provided by Sigma-Aldrich (St. Louis, MO) or Biosolve BV (Valkenswaard, the Netherlands). The enzyme - a mixture of $\beta$-glucuronidase and sulfatase type HP-2 from $H$. pomatia - was obtained from Sigma-Aldrich (cat. no. G7017, lot no. SLBF3495; PCode 1001736103, purchased December 2014). Reference phytoestrogens (apigenin, genistein, daidzein, biochanin A, naringenin, formononetin, naringenin, and equol) were purchased from Sigma-Aldrich, and internal standards genistein-d4 (4-hydroxyphenyl-2,3,5,6$\mathrm{d} 4$ ) and daidzein-d4 (4-hydroxyphenyl-2,3,5,6-d4) were from CDN Isotopes (EQ Laboratories GmbH, Augsburg, Germany). Deionized water was prepared using a Milli-Q water system (Millipore, Billerica, MA). The ultrafiltration column (Vivaspin 500; 10,000 molecular weight cut-off, MWCO, polycarbonate housing, polyethersulfone membrane) was purchased from Sartorius (Stedim Biotech GmbH, Goetting, Germany).

\section{Milk Samples}

Milk samples from 4 different dairy farms (A, B, C, D) were investigated. Samples were collected on site, and aliquots of milk were stored at $-20^{\circ} \mathrm{C}$ in plastic tubes until further processing. Different feed was used at farms with variable content that predominantly included silage from plants producing phytoestrogens (for more details, see Supplementary Materials; http:// dx.doi.org/10.3168/jds.2016-10926).

\section{Standard Solutions}

Standard solutions of phytoestrogens and internal standards of genistein-d4 and daidzein-d4 were prepared at a concentration of $1 \mathrm{mg} / \mathrm{mL}$ in dimethyl sulfoxide. The calibration solutions were obtained by diluting each phytoestrogen in methanol to concentrations ranging from 0.05 to $500 \mathrm{ng} / \mathrm{mL}$ for all analyzed compounds and then spiking the solutions with $20 \mathrm{ng} /$ $\mathrm{mL}$ of both internal standards (genistein-d4, daidzeind4). The calibration solutions were stored at $-20^{\circ} \mathrm{C}$ for a maximum of 1 mo.

\section{Extraction Process}

The procedure for extracting phytoestrogens from the analyzed matrix was slightly modified from that used by Krajčová et al. (2010). Replicate samples of milk $(1 \mathrm{~mL})$ or water (i.e., a blank solution) were each mixed with $2 \mathrm{~mL}$ of acetone. After $3 \mathrm{~min}$ of vortexing followed by centrifugation $\left(5 \mathrm{~min} ; 4,000 \times g ; 18^{\circ} \mathrm{C}\right)$, the acetone was evaporated from the supernatant under a stream of nitrogen $\left(22^{\circ} \mathrm{C}\right)$. Then, $3 \mathrm{~mL}$ of acetate buffer $(0.1 \mathrm{M}, \mathrm{pH} 5)$ and $50 \mu \mathrm{L}$ of hydrolytic enzyme ( $\beta$-glucuronidase/sulfatase type HP-2 from $H$. pomatia) were added to release the phytoestrogens from their conjugated forms into aglycones ( $16 \mathrm{~h}$ of incubation at $37^{\circ} \mathrm{C}$ ). The internal standards of genistein-d 4 and daidzein-d4 were then added (final concentrations of $20 \mathrm{ng} /$ $\mathrm{mL}$ for each compound), and the mixture was extracted 2 times with $3 \mathrm{~mL}$ of ethylacetate. The organic phases were pooled and sequentially frozen, first at $-20^{\circ} \mathrm{C}$ for $10 \mathrm{~min}$ and then at $-80^{\circ} \mathrm{C}$ for another $10 \mathrm{~min}$. This approach accelerated the separation of residual lipid from the liquid phase. The cooled sample was cleared of lipids by centrifugation $\left(5 \mathrm{~min}, 4,000 \times g ; 0^{\circ} \mathrm{C}\right)$, and the solvent was evaporated under a stream of nitrogen to dryness. The dried extract was redissolved in $1 \mathrm{~mL}$ of methanol using an ultrasonic bath (5 min), and the extracts were kept at $-20^{\circ} \mathrm{C}$ until analyses by LC-MS/ MS.

To analyze the contents of phytoestrogens in the enzyme, $12.5 \mu \mathrm{L}$ of the enzyme solution (as supplied by the manufacturer) was evaporated to dryness under a stream of nitrogen, and $110 \mu \mathrm{L}$ of methanol and $2.5 \mu \mathrm{L}$ of a mixture of internal standards in methanol (final concentrations of $20 \mathrm{ng} / \mathrm{mL}$ for each compound) were 
added. The precipitated proteins were separated by centrifugation $\left(10 \mathrm{~min} ; 15,000 \times g ; 18^{\circ} \mathrm{C}\right)$, and samples in glass inserts were stored at $-20^{\circ} \mathrm{C}$ until analyses by LC-MS/MS. Extraction and analysis were performed in 3 replicates.

In addition, ultrafiltration of the enzyme was employed to study the forms in which phytoestrogens were present (i.e., bound to protein fraction or freely dissolved). A sample of enzyme $(50 \mu \mathrm{L})$ in 3 replicates was centrifuged in an ultrafiltration column (Vivaspin MWCO 10,000) for $20 \min \left(15,000 \times g ; 18^{\circ} \mathrm{C}\right)$. Then, a $12.5-\mu \mathrm{L}$ aliquot of the filtrate (the low molecular fraction) or $12.5 \mu \mathrm{L}$ of the protein fraction was evaporated to dryness and diluted with $110 \mu \mathrm{L}$ of methanol, and internal standards were added as previously described (final concentrations of $20 \mathrm{ng} / \mathrm{mL}$ ). After the mixtures were vortexed, the precipitates were separated by centrifugation $\left(20 \mathrm{~min} ; 15,000 \times g ; 18^{\circ} \mathrm{C}\right)$, and the supernatants were kept in glass inserts at $-20^{\circ} \mathrm{C}$ until analyses by LC-MS/MS.

\section{Liquid Chromatography}

Analyses were performed with an Agilent 1290 series HPLC apparatus (Agilent Technologies, Waldbronn, Germany) consisting of a vacuum degasser, a binary pump, an autosampler, and a thermostatically controlled column compartment kept at $30^{\circ} \mathrm{C}$. The analytical column was a $100 \times 2 \mathrm{~mm}$ Phenomenex LUNA C-18 end-capped with $3-\mu \mathrm{m}$ particles and with a Phenomenex SecureGuard C18 guard column (Phenomenex, Torrance, CA). The mobile phase consisted of water (solvent A) and methanol (solvent B) at a flow rate of $0.25 \mathrm{~mL} / \mathrm{min}$. The gradient elution was as follows: 0 to $2.5 \mathrm{~min}, 20$ to $65 \% \mathrm{~B} ; 2.5$ to $5.5 \mathrm{~min}, 65$ to $70 \% \mathrm{~B} ; 5.5$ to $10 \mathrm{~min}, 70$ to $100 \% \mathrm{~B} ; 10$ to $12 \mathrm{~min}$, $100 \% \mathrm{~B} ; 12.01$ to $16 \mathrm{~min}, 20 \% \mathrm{~B}$. The injection volume was $5 \mu \mathrm{L}$.

\section{Mass Spectrometry}

The detection of phytoestrogens was carried out on an AB Sciex 5500 QTrap mass spectrometer (AB Sciex, Concord, ON, Canada) with electrospray ionization. The ion source was operated in negative mode. The ionization parameters were as follows: capillary voltage, 4,500 V; drying gas temperature, $450^{\circ} \mathrm{C}$; drying gas pressure, $275.8 \mathrm{kPa}$; nebulizer pressure, $275.8 \mathrm{kPa}$; and curtain gas pressure, $103.4 \mathrm{kPa}$. The scheduled multiple reaction monitoring (MRM) mode was used for detection. The acquisition parameters of all analytes (including internal standards) are summarized in Table 1 . The obtained chromatograms were processed using Analyst 1.6.1 software (AB Sciex, Framingham,
MA). The limits of detection (LOD) and quantification (LOQ) were determined as the concentrations of phytoestrogens with a signal:noise ratio of $3: 1$ and 10:1, respectively. All analyses were repeated in 3 independent experiments (each run in 2 replicates). The results are expressed as mean \pm standard errors of the mean (n $=3$ ). Calibration of phytoestrogens $(0.05-500 \mathrm{ng} / \mathrm{mL})$ containing internal standards $(20 \mathrm{ng} / \mathrm{mL})$ was used for quantification. For each analyte, quantification was based on the most intensive MRM diagnostic transition, considering relative signals between each analyte and both internal standards.

\section{Statistical Analysis}

Statistical analyses were done with Statistica (StatSoft Inc., Tulsa, OK). Relationships between phytoestrogen concentrations in feed and milk were assessed by Pearson correlation, and differences between the phytoestrogens in milks and blanks were tested by oneway ANOVA followed by the Dunnett post hoc test. $P$ values $<0.05$ were considered statistically significant.

\section{RESULTS}

\section{Method Validation}

Calibration curves based on the ratio between the peak area of each analyte and both internal standards were used for the quantification of phytoestrogens (biochanin A, coumestrol, daidzein, equol, formononetin, genistein, naringenin, and apigenin). The calibrations were linear within the range 0.05 to $500 \mathrm{ng} / \mathrm{mL}$ with a coefficient of determination $\mathrm{R}^{2}>0.999$ for all measured analytes. The calibration curves were prepared using 6 replicates of 9 concentration points. Relative standard error (RSE) did not exceed $12 \%$ for any of the analytes within the range of concentrations 0.05 to $500 \mathrm{ng} / \mathrm{mL}$ (Supplementary Figure S1; http://dx.doi.org/10.3168/ jds.2016-10926). The concentration range 0.05 to 500 $\mathrm{ng} / \mathrm{mL}$ was satisfactory for quantifying all phytoestrogen amounts in milk samples. The sensitivity based on signal to noise ratio of the method was different for analyzed phytoestrogens (see LOQ values in Table 1), but for analyses in milk a single limit of quantification $0.05 \mathrm{ng} / \mathrm{mL}$ (same for all phytoestrogens) was used.

Intraday ( 6 injections within $1 \mathrm{~d} ; \mathrm{n}=6$ ) and interday precision (6 injections per $4 \mathrm{~d}$; $\mathrm{n}=24$ ) expressed as RSE were determined for 2 standard concentrations, which corresponded to natural phytoestrogen concentrations (5 and $10 \mathrm{ng} / \mathrm{mL}$, with fresh solutions prepared daily). The intra- and interday RSE did not exceed 4.8 and $3.6 \%$, respectively, for any analyzed phytoestrogen. A blank solution was repeatedly injected to LC after 
at least 10 samples to check for cross-contamination and to confirm no traces of phytoestrogens or internal standards. Accuracy of the methods was calculated for the same 2 standard concentrations ( 5 and $10 \mathrm{ng} / \mathrm{mL}$ ). In the intraday experiments, the maximum mean value was observed for $5 \mathrm{ng} / \mathrm{mL}$ of apigenin (measured concentration $5.7 \mathrm{ng} / \mathrm{mL}$; i.e., 114\%), and the minimum mean value was observed for $10 \mathrm{ng} / \mathrm{mL}$ of formononetin (measured concentration $9.3 \mathrm{ng} / \mathrm{mL}$; i.e., $93 \%$ ). In the interday experiments, the maximum mean value was observed for $10 \mathrm{ng} / \mathrm{mL}$ of formononetin (measured concentration $10.8 \mathrm{ng} / \mathrm{mL} ; 108 \%$ ), and the minimum mean value was observed for $5 \mathrm{ng} / \mathrm{mL}$ of equol (measured concentration $4.5 \mathrm{ng} / \mathrm{mL} ; 90 \%$ ).

For each analyte and internal standards, the ratio of the signal of quantification transition and the one used for confirmation (i.e., qualification ion; Table 1) remained stable during the validation of standard solutions as well as during analyses of milk samples with values that did not exceed $6 \%$ RSE. The precision of the method was also evaluated according to the retention time repeatability for which the relative standard errors were always lower than $1.5 \%$ for all analyzed phytoestrogens.

\section{Concentrations of Phytoestrogens in Milk Samples and Blank Solutions}

The identification of the analytes was based on the retention time and presence of 2 diagnostic MRM tran- sitions and their ratio (Table 1). Phytoestrogens were analyzed in blank (solvent) samples with and without enzyme addition and in milk samples with and without enzyme addition (each of the samples contained internal standards). Diagnostic ion chromatograms of main phytoestrogens detected in one of the blank samples (i.e., water extracted with enzyme) are presented in Figure 1. The results clearly demonstrate that the presence of phytoestrogens in blanks originated from enzyme contamination.

Figure 2 compares example chromatograms of phytoestrogens in selected natural bovine milk (sample A) hydrolyzed with an enzyme and the corresponding blanks (i.e., water processed the same way as the milk sample including the addition of an enzyme) and in the processed water without the enzyme addition in which no phytoestrogens were found (Figure 2C).

The concentrations of most phytoestrogens in the milk sample corresponded to the concentrations detected in the blank processed with the enzyme (Table 2 ). The only exception was equol, which was found in sample $\mathrm{A}$ at the highest concentration, $175.6 \mathrm{ng} / \mathrm{mL}$ (mean value of 3 repeated analyses). Equol concentrations in other milk samples were 10.7, 65.0, and 10.4 $\mathrm{ng} / \mathrm{mL}$ for samples $\mathrm{B}, \mathrm{C}$, and $\mathrm{D}$, respectively. A very low concentration of equol $(0.2 \pm 0.03 \mathrm{ng} / \mathrm{mL} ; \mathrm{n}=12)$ was detected in the blank treated with the enzyme.

From the other analytes, the highest concentrations (both in milk and blank water) were observed for apigenin $(380 \mathrm{ng} / \mathrm{mL})$. The mean concentrations of the

Table 1. Chromatographic and MS parameters for analyzed phytoestrogens

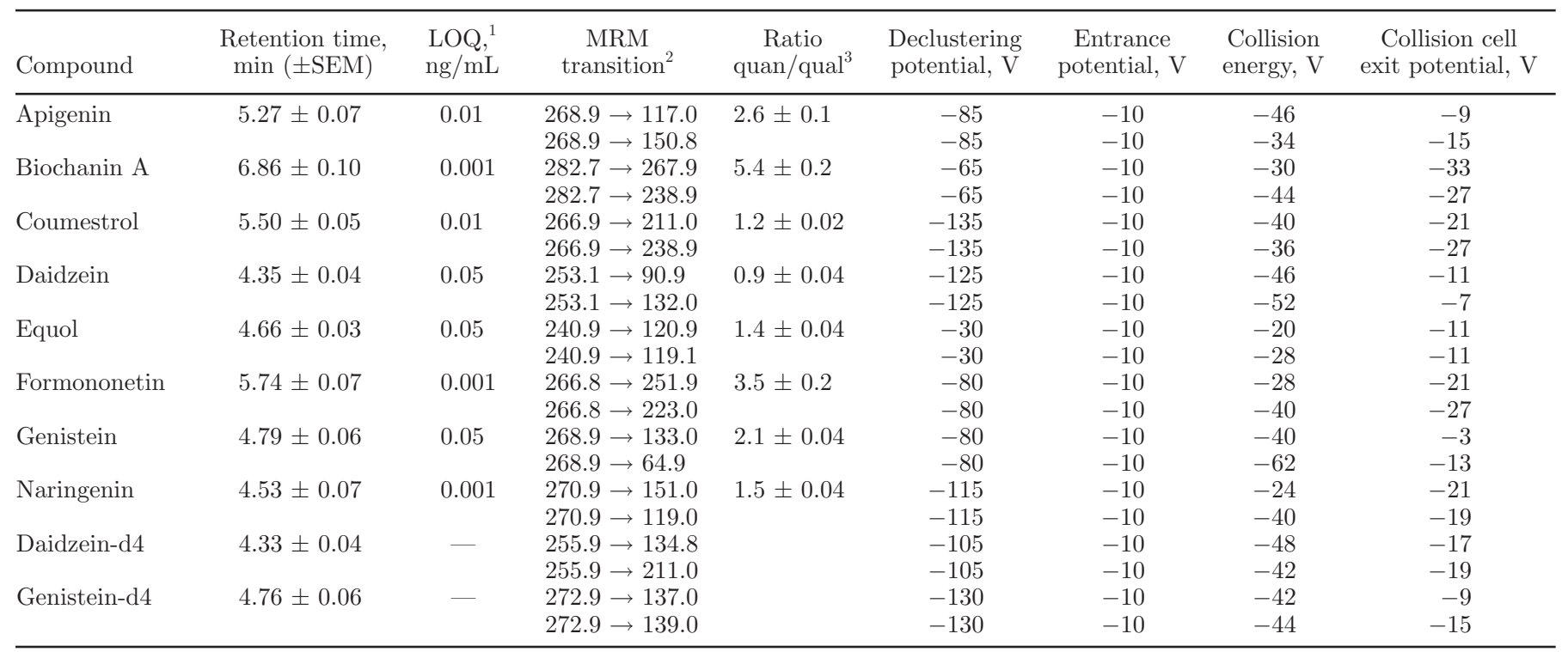

\footnotetext{
${ }^{1}$ Limit of quantification.

${ }^{2}$ Multiple reaction monitoring (MRM) transitions for 2 ions - quantification (upper row) and qualification.

${ }^{3}$ Ratio of the signal of quantification and qualification ion as mean \pm SEM; $n=6$.
} 
other detected phytoestrogens (genistein, daidzein, biochanin A, naringenin, and formononetin) ranged from 5 to $95 \mathrm{ng} / \mathrm{mL}$ in both the milk sample and the blank. Coumestrol was found at low concentrations (i.e., 1.7 $\pm 0.1 \mathrm{ng} / \mathrm{mL})$.

\section{Distribution of Phytoestrogens in Commercially Available Enzyme Solution}

Based on the observations described above, we further investigated the presence of isoflavones in the com-
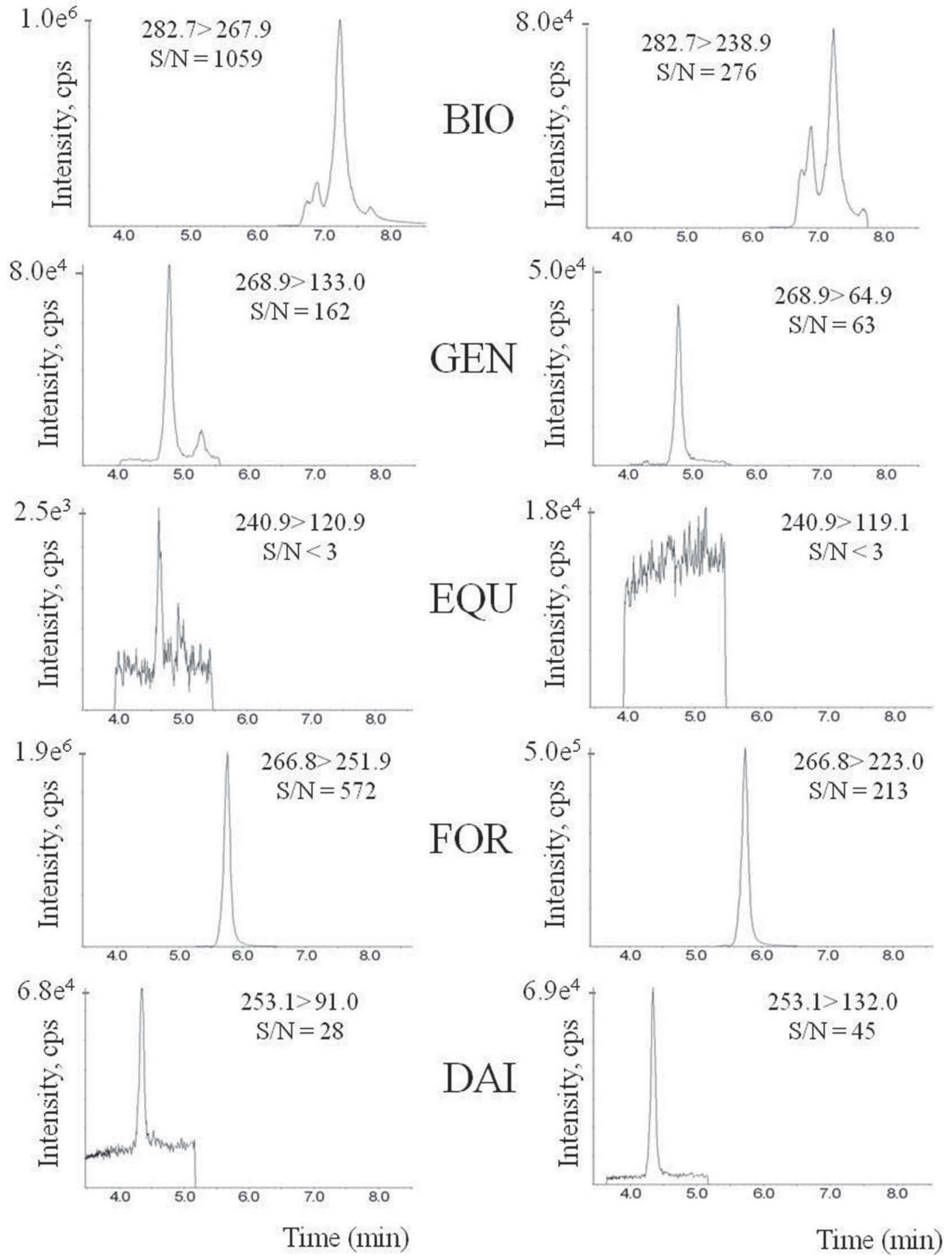

Figure 1. Diagnostic ion chromatograms of main phytoestrogens in a blank sample (water processed with the enzyme). Left panels show quantification multiple reaction monitoring $(\mathrm{MRM})$ transitions; right panels show qualification $\mathrm{MRM}$ transitions. $\mathrm{BIO}=\mathrm{biochanin} \mathrm{A}$; $\mathrm{GEN}=$ genistein; $\mathrm{EQU}=$ equol (unidentified); $\mathrm{FOR}=$ formononetin; DAI = daidzein; $\mathrm{S} / \mathrm{N}=$ signal-to-noise ratio; cps $=$ counts per second. 

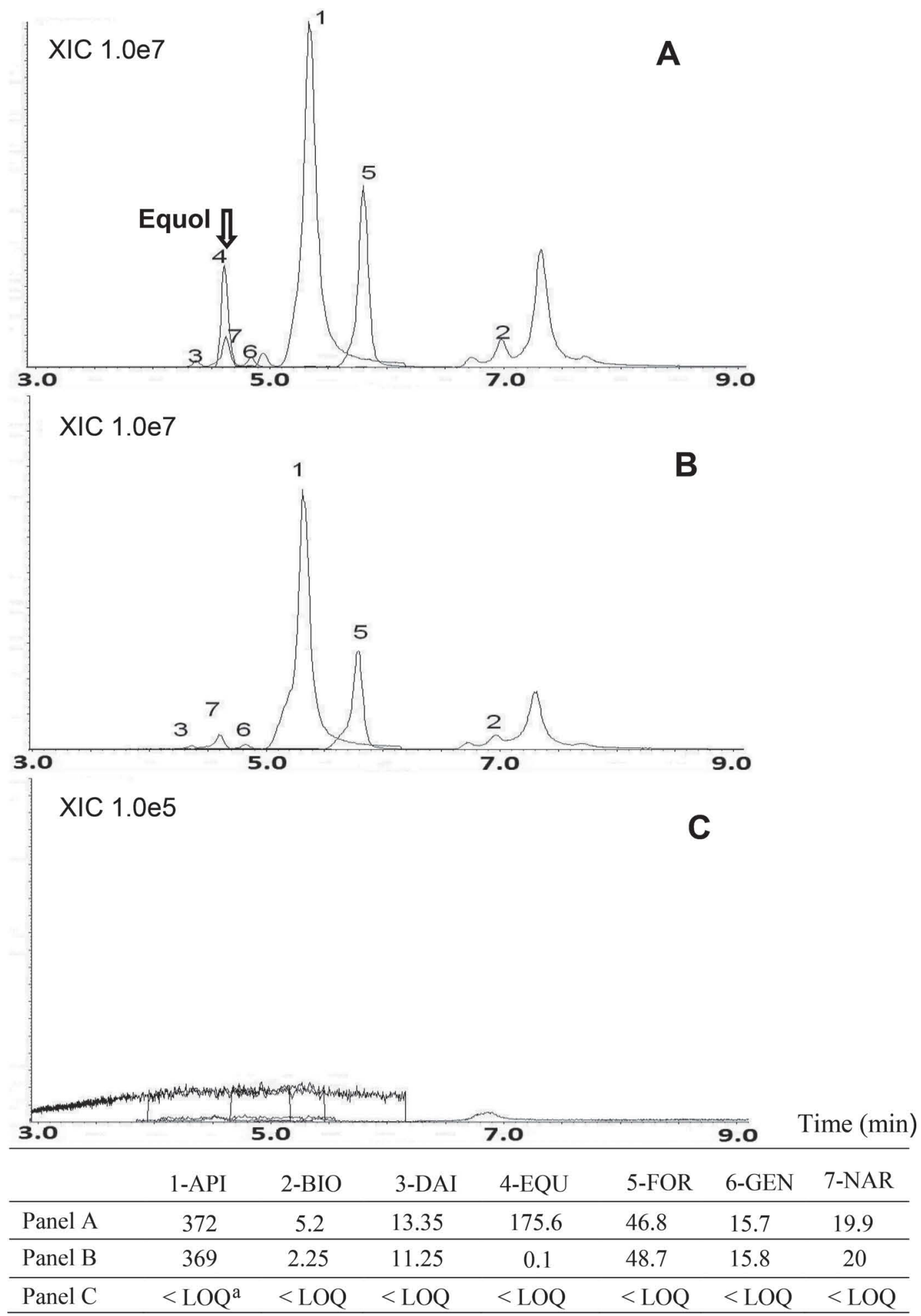

Figure 2. Overlay of liquid chromatography-tandem MS (LC-MS/MS) chromatograms of phytoestrogen analyses: (A) milk sample hydrolyzed by enzyme $(50 \mu \mathrm{L}$; an arrow points to equol, which is missing in panel B); (B) processed water with enzyme; (C) processed water only. Peaks in chromatograms correspond to phytoestrogens: $1=$ apigenin (API); $2=$ biochanin A (BIO); $3=$ daidzein (DAI); $4=$ equol (EQU); 5 $=$ formononetin $(\mathrm{FOR}) ; 6=$ genistein $(\mathrm{GEN}) ; 7=$ naringenin $(\mathrm{NAR})$. The table compares concentrations $(\mathrm{ng} / \mathrm{mL})$ of phytoestrogens in samples

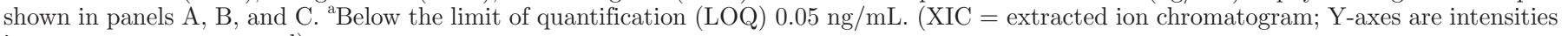
in $\mathrm{cps}=$ counts per second). 


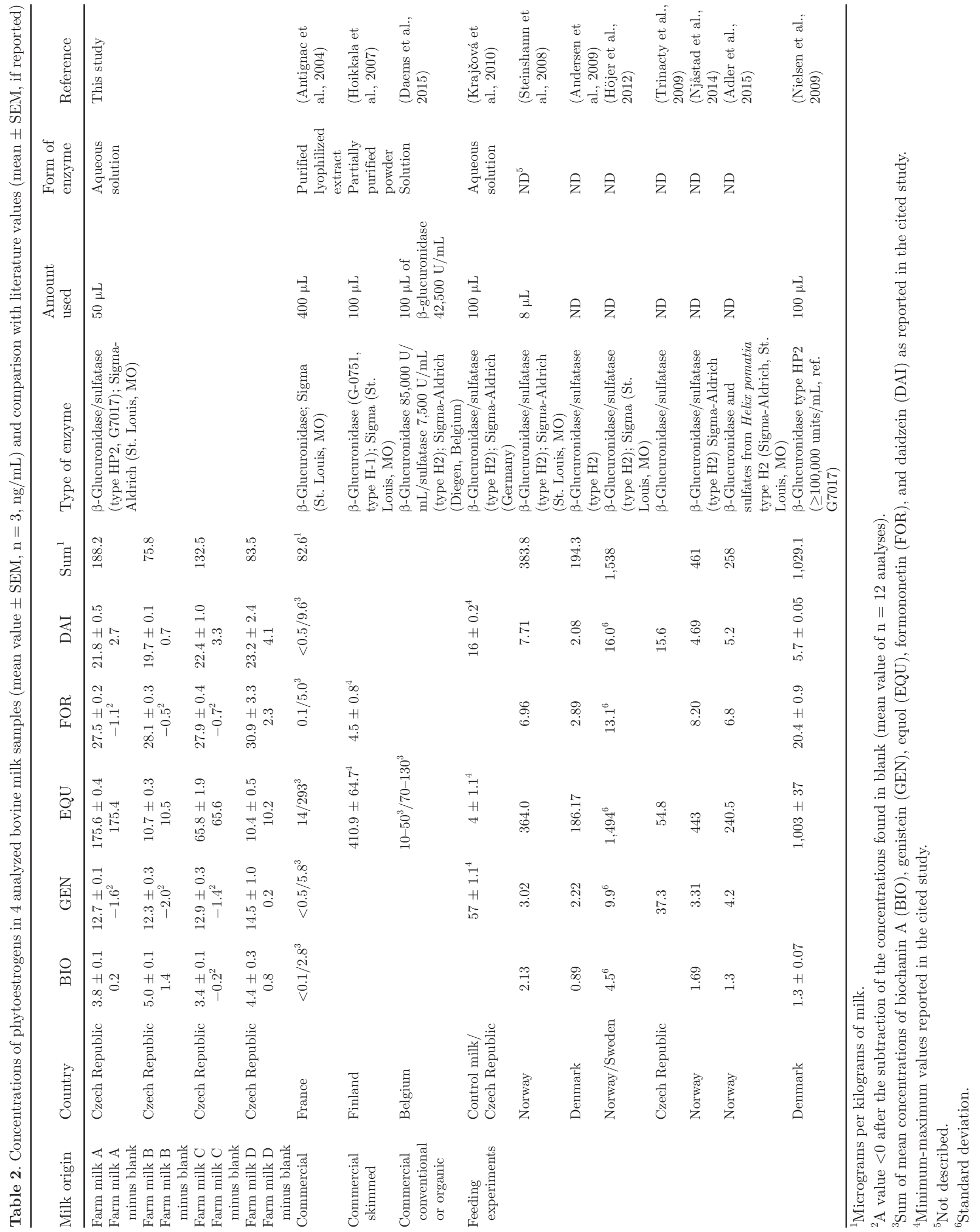


Table 3. The concentration of main phytoestrogens $(\mathrm{ng} / \mathrm{mL})$ in $\beta$-glucuronidase/sulfatase type HP-2 from Helix pomatia (G7017, SigmaAldrich, St. Louis, MO) expressed as mean \pm SEM of $n=3$ in (1) the enzyme solution, (2) purified enzyme (ultrafiltration), and (3) the low molecular fraction of the enzyme solution

\begin{tabular}{|c|c|c|c|c|c|}
\hline Item & Biochanin A & Genistein & Equol & Formononetin & Daidzein \\
\hline Purified enzyme solution (ultrafiltration; salt-free fraction) & $128 \pm 2.9$ & $285 \pm 13$ & $2.8 \pm 0.1$ & $863 \pm 110$ & $487 \pm 18$ \\
\hline Low molecular fraction of enzyme solution (ultrafiltrate) & $0.1 \pm 0.0$ & $0.7 \pm 0.1$ & $<\mathrm{LOQ}^{1}$ & $0.07 \pm 0.07$ & $<\mathrm{LOQ}$ \\
\hline
\end{tabular}

${ }^{1}$ Below the limit of quantification (LOQ) $0.05 \mathrm{ng} / \mathrm{mL}$.

mercial enzyme solution after ultrafiltration. As shown in Table 3, the protein (salt-free) fraction contained about the same isoflavone concentrations as the original enzyme. Isoflavones in the enzyme were present mostly as aglycones (i.e., not glycoside conjugates), as revealed by comparison of the extractions with and without the hydrolytic step (hydrolysis followed by extraction with ethylacetate did not change isoflavone concentrations in the enzyme). From the studied glycosides (conjugated forms) of phytoestrogens (i.e., genistin, daidzin, ononin), only genistin was detected in the enzyme at a low but detectable concentration close to the limit of detection (data not shown).

\section{DISCUSSION}

The present study revealed that the commercially available aqueous solution of hydrolytic enzyme $\beta$-glucuronidase/sulfatase from $H$. pomatia, which has traditionally been used by many authors in the analysis of isoflavones in milk (Steinshamn et al., 2008; Andersen et al., 2009; Trinacty et al., 2009; Krajčová et al., 2010; Höjer et al., 2012; Njåstad et al., 2014; Adler et al., 2015), contains high concentrations of these compounds, which might interfere with the analysis of phytoestrogens in milk. As shown in Table 2, the concentrations (mean values with SEM) detected in all studied milk samples hydrolyzed with the enzyme and analyzed in 3 replicates ranged from 12.3 to $14.5 \mathrm{ng} / \mathrm{mL}$ for genistein, 19.7 to $23.2 \mathrm{ng} / \mathrm{mL}$ for daidzein, 27.5 to $30.9 \mathrm{ng} / \mathrm{mL}$ for formononetin, and 3.4 to $5 \mathrm{ng} / \mathrm{mL}$ for biochanin A (before subtraction of the blank; i.e., water processed with the enzyme). Similar concentration ranges for genistein $(9-57 \mathrm{ng} / \mathrm{mL})$, daidzein (15.6-16 $\mathrm{ng} / \mathrm{mL})$, formononetin $(20.4 \mathrm{ng} / \mathrm{mL})$, and biochanin A $(2.1-4.5 \mathrm{ng} / \mathrm{mL})$ were observed in other studies that analyzed isoflavones in milk (Steinshamn et al., 2008; Nielsen et al., 2009; Trinacty et al., 2009; Krajčová et al., 2010; Höjer et al., 2012). The use of enzymatic hydrolysis could substantially affect the absolute concentrations of genistein, daidzein, formononetin, and biochanin $\mathrm{A}$, which are the most frequently reported isoflavones in samples such as milk or milk products and occur at low concentrations.
The present study is in line with an earlier investigation by Taylor et al. (2005), who found contamination of $\beta$-glucuronidase from $H$. pomatia (HP-2, the same enzyme as used in the present work) by genistein at concentrations higher than $10 \mathrm{ng} / \mathrm{mL}$. To our knowledge, the origin of the phytoestrogens in this commercially available and widely used crude mixture of enzymes has not been investigated in detail. The phytoestrogens may originate directly from the feed of Roman snails, whose digestive gland is used as the source of hydrolytic juice (Billett, 1954). Other studies have also mentioned phytoestrogen contamination of $\beta$-glucuronidase from $H$. pomatia, and researchers have suggested possible improvements such as advanced solid-phase extraction precleaning (Grace and Teale, 2006; Setchell et al., $2001,2002)$ or use of $\beta$-glucuronidase/sulfatase from other organisms such as Escherichia coli (Moors et al., 2007). The most obvious and expected approach would be to consider analyses of appropriate blanks (as shown in the present study; e.g., solvent with enzyme added). Cross-contamination could be minimized by optimization of the enzyme volume needed for effective hydrolysis, considering the enzyme activity and duration of the hydrolytic step. As shown in Table 2, variable amounts $(8-400 \mu \mathrm{L})$ of the enzyme with different nominal activities (units $/ \mathrm{mL}$ ) have been used for different volumes of milk sample in different studies. However, Table 2 reveals that details and validation of the protocols used (including possible contamination of the hydrolytic enzyme) have only rarely been reported by dairy science researchers. Indeed, only the results of analyses of the isoflavone metabolite equol, the first phytoestrogen identified in milk (reviewed recently by Kalač, 2013) and recognized as a major estrogen in milk and milk products (Kalač, 2011), can be considered reliable in our study. After hydrolysis by $\beta$-glucuronidase from $H$. pomatia (HP-2), the levels of biochanin A, daidzein, genistein, and formononetin found in the milk samples from 4 different farms and levels of these compounds in blanks were comparable and did not show any statistically significant differences. Only the equol concentrations (ranging 10.7-175.2 ng/mL in the milk samples) were significantly different from blanks (ANOVA with Dunnett test, $P<0.0001)$. 
In addition, phytoestrogens were also analyzed in feed from different farms. The extraction method and average concentrations of analyzed phytoestrogens (biochanin A, coumestrol, daidzein, daidzin, formononetin, genistein, and genistin) are shown in Supplementary Table S1 (http://dx.doi.org/10.3168/jds.2016-10926). The sum of phytoestrogens in feed samples varied from 721 to $3,718 \mathrm{mg} / \mathrm{kg}$ of DM. The highest total phytoestrogen concentrations were found in feed from farm A, which corresponded to the highest concentration of equol found in milk from the same farm. Indeed, when all 4 farms were considered, significant correlations were observed between equol in milk and formononetin in feed (Pearson $\mathrm{r}=0.997, P<0.05$ ); formononetin is a methoxylated precursor known to be transformed to equol in cows (Kalač, 2013). A significant correlation was also found between equol in milk and another methoxylated isoflavone, biochanin A, in feed (Pearson $\mathrm{r}=0.987, P<0.05)$. Interestingly, concentrations of daidzein (hydroxylated equol precursor; Kalač, 2013), genistein, and the sum of phytoestrogens in feed were not correlated with equol in milk (Pearson correlation coefficient $\mathrm{r}, P>0.05$ ). This finding is particularly interesting because daidzein has been suggested to be another precursor of equol (Moors et al., 2007; Kalač, 2013). The concentrations of formononetin in feed from farms A, C, D, and B (decreasing order) were 768, 201, 5.1 , and $3.5 \mathrm{mg} / \mathrm{kg}$, respectively (Supplementary Table $\mathrm{S} 1$ ), which corresponded to equol concentrations in milk from the same farms: 176, 66, 10.2, and $10.5 \mathrm{ng} /$ $\mathrm{mL}$, respectively (Table 2 ).

This study indicates that equol was the only component affected by the differences in feed used at different farms where milk samples were collected. Similar observation (i.e., no differences in daidzein and genistein, and increasing equol concentrations with higher content of soy in cows feed) were observed by other authors (Krajčová et al., 2010). Nevertheless, several other studies indicate that concentrations of other phytoestrogens in milk can be affected by feed composition (Steinshamn et al., 2008; Andersen et al., 2009; Trinacty et al., 2009; Höjer et al., 2012; Njåstad et al., 2014; Adler et al., 2015).

\section{CONCLUSIONS}

Contamination by isoflavones (genistein, daidzein, formononetin, and biochanin A) and their metabolite equol and by flavones (naringenin and apigenin), the conjugated form of isoflavones (genistin), and coumestrol was revealed in the commercially available hydrolytic enzyme that is often used for the extraction of isoflavones from milk or other complex samples. The highest concentration was found for apigenin (as high as $6 \mu \mathrm{g} / \mathrm{mL}$ of enzyme solution). The concentrations of enzyme contaminants (especially daidzein and genistein) could have significantly influenced the results of analyses of isoflavones in milk. From the analyzed compounds in our study, only equol was confirmed in cow milk, being a reliable marker of phytoestrogens originating from cow feed (and not affected by the use of the extraction enzyme). A thorough assessment of the literature indicates that previous studies rarely reported important details on extraction procedure and analyses of blanks and might thus have overestimated phytoestrogen concentrations depending on the type and amount of the extraction enzyme used.

\section{ACKNOWLEDGMENTS}

The research was supported by the Ministry of Education of the Czech Republic projects LO1214 and LM2011028. Authors especially acknowledge support provided by Aleš Pavlík, Mendel University, Brno, Czech Republic. The authors declare no conflicts of interest.

\section{REFERENCES}

Adler, S. A., S. Purup, J. Hansen-Møller, E. Thuen, and H. Steinshamn. 2015. Phytoestrogens and their metabolites in bulktank milk: Effects of farm management and season. PLoS One 10:e127187. http://dx.doi.org/10.1371/journal.pone.0127187.

Andersen, C., M. R. Weisbjerg, J. Hansen-Møller, and K. Sejrsen. 2009. Effect of forage on the content of phyto-oestrogens in bovine milk. Animal 3:617-622. http://dx.doi.org/10.1017/S1751731108003698.

Antignac, J.-P., R. Cariou, B. Le Bizec, and F. André. 2004. New data regarding phytoestrogens content in bovine milk. Food Chem. 87:275-281. http://dx.doi.org/10.1016/j.foodchem.2003.12.013.

Antignac, J.-P., R. Cariou, B. Le Bizec, J.-P. Cravedi, and F. Andre. 2003. Identification of phytoestrogens in bovine milk using liquid chromatography/electrospray tandem mass spectrometry. Rapid Commun. Mass Spectrom. 17:1256-1264. http://dx.doi. org $/ 10.1002 / \mathrm{rcm} .1052$.

Antignac, J.-P., I. Gaudin-Hirret, H. Naegeli, R. Cariou, C. Elliott, and B. Le Bizec. 2009. Multi-functional sample preparation procedure for measuring phytoestrogens in milk, cereals, and babyfood by liquid-chromatography tandem mass spectrometry with subsequent determination of their estrogenic activity using transcriptomic assay. Anal. Chim. Acta 637:55-63. http://dx.doi. org/10.1016/j.aca.2008.11.050.

Billett, F. 1954. The $\beta$-glucuronidase of the Roman snail (Helix pomatia). Biochem. J. 57:159-162.

Daems, F., C. Jasselette, J.-M. Romnee, V. Planchon, G. Lognay, and É. Froidmont. 2015. Validating the use of an ultra-performance liquid chromatography with tandem mass spectrometry method to quantify equol in cow's milk. Dairy Sci. Technol. 95:303-319. http://dx.doi.org/10.1007/s13594-015-0209-6.

Deceuninck, Y., E. Bichon, F. Monteau, G. Dervilly-Pinel, J. P. Antignac, and B. Le Bizec. 2013. Fast and multiresidue determination of twenty glucocorticoids in bovine milk using ultra high performance liquid chromatography-tandem mass spectrometry. J. Chromatogr. A 1294:76-86. http://dx.doi.org/10.1016/j.chroma.2013.04.019.

Grace, P. B., and P. Teale. 2006. Purification of the crude solution from Helix pomatia for use as $\beta$-glucuronidase and aryl sulfatase in phytoestrogen assays. J. Chromatogr. B Analyt. Tech- 
nol. Biomed. Life Sci. 832:158-161. http://dx.doi.org/10.1016/j. jchromb.2005.12.022.

Hoikkala, A., E. Mustonen, I. Saastamoinen, T. Jokela, J. Taponen, H. Saloniemi, and K. Wähälä. 2007. High levels of equol in organic skimmed Finnish cow milk. Mol. Nutr. Food Res. 51:782-786. http://dx.doi.org/10.1002/mnfr.200600222.

Höjer, A., S. Adler, S. Purup, J. Hansen-Møller, K. Martinsson, H. Steinshamn, and A.-M. Gustavsson. 2012. Effects of feeding dairy cows different legume-grass silages on milk phytoestrogen concentration. J. Dairy Sci. 95:4526-4540. http://dx.doi.org/10.3168/ jds.2011-5226.

Kalač, P. 2011. The effects of silage feeding on some sensory and health attributes of cow's milk: A review. Food Chem. 125:307317. http://dx.doi.org/10.1016/j.foodchem.2010.08.077.

Kalač, P. 2013. Fresh and ensiled forages as a source of estrogenic equol in bovine milk: A review. Czech J. Anim. Sci. 58:296-303.

Krajčová, A., V. Schulzová, J. Lojza, L. Křížová, and J. Hajšlová. 2010. Phytoestrogens in bovine plasma and milk-LC-MS/MS analysis. Czech J. Food Sci. 28:264-274.

Moors, S., M. Blaszkewicz, H. M. Bolt, and G. H. Degen. 2007. Simultaneous determination of daidzein, equol, genistein and bisphenol A in human urine by a fast and simple method using SPE and GCMS. Mol. Nutr. Food Res. 51:787-798. http://dx.doi.org/10.1002/ mnfr.200600289.

Nielsen, T. S., J. V. Nørgaard, S. Purup, X. C. Fretté, and E. C. Bonefeld-Jørgensen. 2009. Estrogenic activity of bovine milk high or low in equol using immature mouse uterotrophic responses and an estrogen receptor transactivation assay. Cancer Epidemiol. 33:61-68. http://dx.doi.org/10.1016/j.canep.2009.04.003.

Njåstad, K. M., S. A. Adler, J. Hansen-Moller, E. Thuen, A.-M. Gustavsson, and H. Steinshamn. 2014. Gastrointestinal metabolism of phytoestrogens in lactating dairy cows fed silages with different botanical composition. J. Dairy Sci. 97:7735-7750.

Santos-Buelga, C., S. González-Manzano, M. Dueñas, and A. M. González-Paramás. 2012. Analysis and characterisation of flavonoid phase II metabolites. Pages 247-277 in Recent Advances in Polyphenol Research. V. Cheynier, P. Sarni-Manchado, and S. Quideau, ed. Wiley-Blackwell, Chichester, UK. 10.1002/9781118299753. ch11.

Setchell, K. D., N. M. Brown, P. Desai, L. Zimmer-Nechemias, B. E. Wolfe, W. T. Brashear, A. S. Kirschner, A. Cassidy, and J. E. Heubi. 2001. Bioavailability of pure isoflavones in healthy humans and analysis of commercial soy isoflavone supplements. J. Nutr. 131:1362S-1375S. http://dx.doi.org/10.1016/S00052736(00)00142-5.

Setchell, K. D. R. N. M. Brown, L. Zimmer-Nechemias, W. T. Brashear, B. E. Wolfe, A. S. Kirschner, and J. E. Heubi. 2002. Evidence for lack of absorption of soy isoflavone glycosides in humans, supporting the crucial role of intestinal metabolism for bioavailability. Am. J. Clin. Nutr. 76:447-453.

Steinshamn, H., S. Purup, E. Thuen, and J. Hansen-Møller. 2008. Effects of clover-grass silages and concentrate supplementation on the content of phytoestrogens in dairy cow milk. J. Dairy Sci. 91:2715-2725. http://dx.doi.org/10.3168/jds.2007-0857.

Taylor, J. I. P. B. Grace, and S. A. Bingham. 2005. Optimization of conditions for the enzymatic hydrolysis of phytoestrogen conjugates in urine and plasma. Anal. Biochem. 341:220-229. http:// dx.doi.org/10.1016/j.ab.2005.03.053.

Trinacty, J., L. Krizova, V. Schulzova, J. Hajslova, and O. Hanus. 2009. The effect of feeding soybean-derived phytoestrogens on their concentration in plasma and milk of lactating dairy cows. Arch. Anim. Nutr. 63:219-229. http://dx.doi.org/10.1080/17450390902859739.

Zafra-Gómez, A., A. Garballo, L. E. García-Ayuso, and J. C. Morales. 2010. Improved sample treatment and chromatographic method for the determination of isoflavones in supplemented foods. Food Chem. 123:872-877. http://dx.doi.org/10.1016/j foodchem.2010.05.009. 